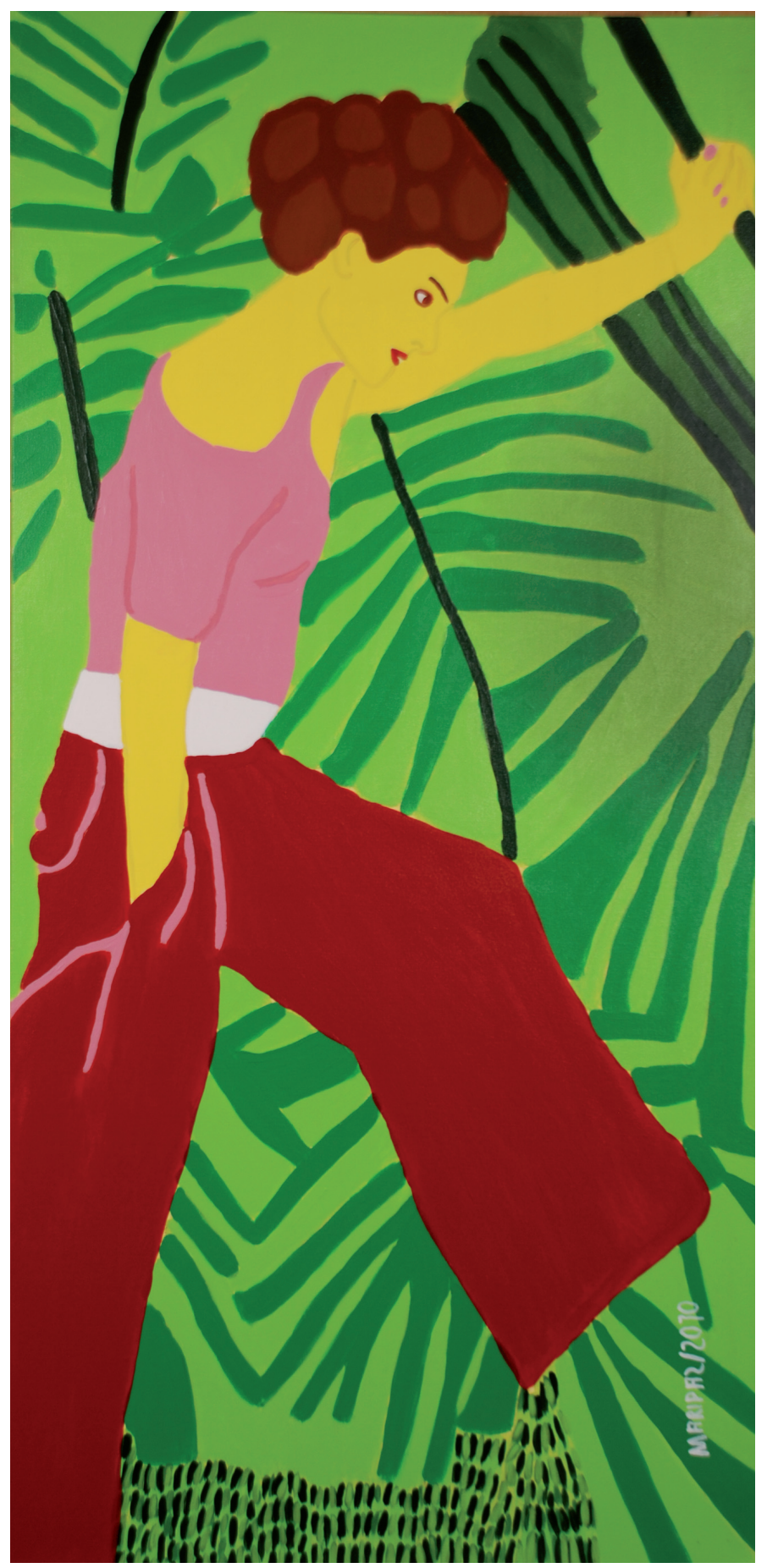




\section{Panamá en nuestra historia constitucional}

Fecha de recepción: 16 de febrero de 2011 - Aprobación: 23 de marzo de 2011

\section{Óscar Alarcón NúÑ̃ez}

\section{Resumen}

Hay quienes tienen aún la creencia de que Panamá nació con lo que hoy es Colombia y que hizo parte de nuestra nación como lo son departamentos tales como Nariño, Antioquia o Bolívar. Mientras el grito de nuestra independencia fue el 20 de julio de 1810, Panamá lo hizo once años después, el 28 de noviembre de 1821.

La verdad fue que en los primeros tiempos de la dominación española Panamá estaba más vinculada a Lima que a la Nueva Granada, tanto que se le conocía como la "garganta del Perú". Sólo en 1717, cuando se creó el virreinato de Santa Fe, por la imposibilidad de gobernar el norte de América del Sur desde Lima, fue cuando Panamá, por primera vez, se puso a depender de la Nueva Granada. Ello se ratificó después por orden expedida en San Lorenzo del Escorial, el 20 de agosto de 1739.

\section{Abstract}

Some people still believe that Panama was originated with what is now Colombia and was part of our nation as well as the departments of Nariño, Antioquia, or Bolivar. While the cry of our independence was on July 20th, 1810, Panama's cry of independence was eleven years later, on November 28th, 1821.

The truth was, during the early days of Spanish rule, Panama was most strongly related to Lima than to New Granada, even to the point that it was known as the "throat of Peru." Only in 1717, when the Viceroyalty of Santa Fe was created, the impossibility of governing the north of South America from Lima made Panama dependent on the New Granada for the first time. This was confirmed later on through order issued in San Lorenzo del Escorial on August 20, 1739.

\section{Palabras Clave}

Panamá, independencia, constitución, separación.

\section{Keywords}

Panama, independence, constitution, separation

\section{INDEPENDENCIA DE PANAMÁ}

El Libertador Simón Bolívar tenía especial admiración por Panamá y por sus gentes, lo cual era correspondido. Tan pronto conoció el acta de independencia con la cual se separaba de España, el 28 de noviembre de 1821, la consideró como "el monumento más glorioso que pueda ofrecer a la historia ninguna provincia americana. Todo está allí consultado: justicia, generosidad, política e interés nacional".

Conseguida su independencia, tres fueron los aspirantes que deseaban quedarse con Panamá: Perú, México y Colombia. El 
primero, por su vinculación estrecha con el istmo; México, que deseaba expandirse por todo Centroamérica, y Colombia.

La figura dominante, al terminar el período colonial en México, fue la de Agustín de Itúrbide, un coronel español y realista que derrotó a los patriotas y que en vez de conservar para el imperio a la Nueva España — como se le llamaba a Méxicoconcibió ideas propias sobre la independencia del país y se volvió contra los españoles. Itúrbide se proclamó como Agustín I, emperador de México. De allí su interés en ampliar su imperio con las naciones centroamericanas que acababan de lograr su independencia, como Panamá.

Una demostración de que por estas épocas Panamá aún no era nuestra, se puede constatar en numerosos documentos que señalan que en 1810, cuando la independencia, la Nueva Granada estaba formada por trece provincias: Santa Fe, Riohacha, Santa Marta, Cartagena, Antioquia, Pamplona, Socorro, Casanare, Tunja, Mariquita, Neiva, Popayán y Chocó (Nóvita).

El Congreso de Cúcuta de 1821, que expidió la Constitución de ese año, consolidó la creación de la República de

\section{Reseña de autor: \\ Óscar Alarcón Núñez (Colombia) \\ osalarcon@yahoo.com \\ Periodista}

Abogado de la Universidad Externado de Colombia con especialización en Ciencias Administrativas en la Universidad de Roma; Derecho Constitucional Comparado y Opinión Pública en Universitá Internazionale degli Studi Sociali de Roma. Autor de los libros: "Los Segundos de a bordo. La vicepresidencia y la designatura" (1999) "Panamá siempre fue de Panamá" (2003) y "Panamá, capital de Colombia" (próximo a publicarse)

HasidoprofesorenDerechoPúblico, HistoriaConstitucional y Derecho Notarial y Registral; Superintendente de Notariado y Registro y Notario. Colaborador de "Semana" y "El Espectador".
Colombia, y así llamó al antiguo virreinato de la Nueva Granada y a la capitanía general de Venezuela y Quito. El territorio abarcaba 2.333.478 kilómetros cuadrados, comprendidos en doce grandes departamentos: Venezuela, Maturín, Orinoco y Zulia (actual Venezuela); Boyacá, Cundinamarca, Magdalena y Cauca (actual Colombia); Quito, Azuay y Guayaquil (actual Ecuador). Entonces no aparecía Panamá. Sólo figuró a partir del 25 de junio de de 1824, por decreto de esa fecha. Se unió a Colombia el 24 de febrero de 1822 .

El panameño Moisés Chong considera que tres fueron las razones que inclinaron a Panamá a sumarse a Colombia: motivos de seguridad política frente a una posible amenaza española desde Puerto Rico o Cuba, bastiones del colonialismo hispánico; el deseo de encontrar una especie de amparo en lo económico, pues las condiciones financieras del istmo, después de los actos de independencia, habían llegado a un punto de verdadera crisis y un sentimiento de solidaridad hemisférica unido a una no oculta admiración por la figura de Bolívar (Chong, 1973, p.121).

A pesar de ser un territorio pequeño, los panameños tenían conciencia de su importancia geográfica ya que contaban con costas en los dos océanos que no se comunicaban fácilmente, razón por la cual para ir de un punto al otro se hacía necesario hacerlo a lomo de mula. Igual pensaba Bolívar, en lo que tenía que ver con su importancia geográfica, tanto que escogió a Panamá como sede de lo que se llamó el Congreso Afictiónico.

En su Carta de Jamaica, del 6 de septiembre de 1815, dice el Libertador:

"Los Estados, del istmo de Panamá hasta Guatemala, formarán quizás una 
asociación. Esta magnifica posición entre los dos mares, podrá ser con el tiempo el emporio del universo. Sus canales acortarán las distancias del mundo: estrecharán los lazos comerciales de Europa, América y Asia; traerán a tan feliz región los tributos de las cuatro partes del globo. ¡Acaso sólo allí podrá fijarse algún día la capital de la tierra! como pretendió Constantino que fuese Bizancio la del antiguo hemisferio".

Por esa ubicación estratégica, Bolívar desde entonces pensaba en Panamá como capital, no de un Estado, sino como ¡capital de la tierra! Y esa idea la manifestó en varias oportunidades. En la misma Carta de Jamaica plantea la realización, en Panamá, de un evento en que participen los nuevos Estados independientes:

“¡Que bello sería que el istmo de Panamá fuese para nosotros lo que el de Corinto para los griegos! Ojalá que algún día tengamos la fortuna de instalar allí un augusto Congreso de los representantes de las repúblicas, reinos e imperios, a tratar y discutir sobre los altos intereses de la paz y de la guerra, con naciones de otras tres partes del mundo".

En 1826, once años después de conocida la Carta de Jamaica, esa propuesta se concretó y el certamen se realizó en donde había pensado el Libertador, en Panamá. Se conoció como el Congreso Afictiónico, palabra que viene de anfictionía que significa "confederación de las antiguas ciudades griegas para asuntos de interés general".

Estando Bolívar en Lima, y al hacer la invitación al certamen, dirigió una circular el 7 de diciembre de 1824 a los gobiernos de las repúblicas de Colombia, Méjico (sic), Río de la Plata, Chile y Guatemala para que concurrieran a Panamá. Para esa fecha ya había ocurrido la batalla de Junín y se estaba en vísperas de la batalla de Ayacucho.

En esa circular vuelve a señalarla como capital ¡del mundo!: "Parece que si el mundo hubiese de elegir su capital, el Istmo de Panamá sería señalado para este augusto destino, colocado, como está en el centro del globo, viendo por una parte al Asia, y por la otra el África y la Europa”.

\section{PRIMERAS SEPARACIONES}

Con la disolución de la Gran Colombia, Panamá pretendía hacer lo mismo de Venezuela y Quito, y en efecto lo hizo. Un boliviano, y además admirador de Bolívar, el general José Domingo Espinar, promovió la separación, entre otras razones porque a él lo habían trasladado como comandante del ejercito de Panamá a Veraguas, lo cual consideraba como una degradación. Promovió una serie de asonadas sin manifestar que ellas tenían relación con su situación personal sino que obedecían a la necesidad de tomar igual actitud que los otros territorios que se habían separado.

El 25 de septiembre de 1830 hizo que los cabildos de seis cantones de Panamá aprobaran una declaración en donde se invitaba al Libertador a encargarse del gobierno constitucional de la República y manifestaba que mientras tomaba esas responsabilidades "la administración departamental le confía al señor general José Domingo Espinar, bajo la denominación de jefe civil y militar con facultades bastante para arreglar los diversos ramos en las reformas que sean necesarias hacer con ellos".

Bolívar no se dejó seducir y, antes por el contrario, invitó al rebelde para que se reintegrase a la república. Pero, cosa rara,
Parece que si el mundo hubiese de elegir su capital, el Istmo de Panamá sería señalado para este augusto destino, colocado, como está en el centro delglobo, viendo por una parte al Asia, y por la otra el África y la Europa. 
ésta se hallaba en una de las consuetudinarias guerras del siglo XIX y por eso Panamá continuó gobernándose sola, a cargo de Espinar, y sólo a finales de ese año, el 10 de diciembre, se anexó nuevamente cuando el Libertador agonizaba en San Pedro Alejandrino y tras consolidarse la dictadura del general venezolano Rafael Urdaneta.

Pero esa sería la primera de las otras cuatro separaciones de Panamá. La segunda fue el 21 de marzo de 1931, cuando aún la primera no se había liquidado completamente. Tuvo como personaje al mismo Espinar, cuando viajó a Veraguas para enfrentarse a José Fábregas, quien pretendía desconocerlo. Dejó en Panamá como encargado al general venezolano Juan Eligio Alzuru, pero la ausencia de aquel condujo a sus enemigos a invitar a éste a que tomara el poder para "restaurar" las libertades suprimidas. En efecto, se sublevó, desterró a Espinar a Guayaquil cuando pretendió reasumir su cargo y convocó a una junta a la que obligó a declarar la independencia. Pero el movimiento duró escasos dos meses, apenas hasta cuando el gobierno central envió al coronel Tomás Herrera (panameño) para sofocar la revuelta. Alzuru fue condenado a muerte y ejecutado el 29 de agosto de 1831 "para pagar en él sus crímenes, y enseñar la manera como deben los pueblos castigar a sus tiranos".

El tercer intento de separación ocurrió cuando la famosa guerra de los Supremos, cuando cada estado escogió su jefe y declaró su independencia. Sobre todo lo hicieron los gobernadores que después se llamarían liberales, en contra del gobierno central presidido por José Ignacio de Márquez, quien, después de pelearse con Santander, resultó unido con quienes luego crearían el
Partido Conservador En el caso de Panamá, escogieron al general Tomás Herrera, de gran prestigio y considerado el más eminente de los panameños del siglo XIX y uno de los más importantes de la Nueva Granada. Allí se decidió, el 18 de noviembre de 1840, que el istmo quedaba libre de compromisos y ligaduras con la Nueva Granada.

Una convención constituyente realizada en marzo de 1841, en donde Tomás Herrera abogó porque se autorizara la reincorporación a la Nueva Granada, señaló que eso se daba siempre y cuando ésta se reorganizara en forma federativa. Se aprobó lo siguiente:

"Artículo 10. Los cantones de las antiguas provincias de Panamá y Veraguas compondrán un estado independiente y soberano que será constituido como tal por la presente convención, bajo el nombre de Estado del Istmo.

"Artículo 2. Si la organización que se diere a la Nueva Granada fuere federal y conveniente a los intereses de los pueblos del istmo, éste formará un Estado de la federación.

Parágrafo. En ningún caso se incorporará el istmo a la República de la Nueva Granada bajo el sistema central".

Se volvió a reincorporar el 31 de diciembre de 1841 pero con la condición expresa de que hubiera un estado federal. Panamá estaba conciente de su importancia geográfica, cual era la de tener costa por los dos océanos y la de ser un punto estratégico para las comunicaciones. Por eso necesitaba que hubiera una facilidad de transporte entre los dos puntos que si bien se hallaban relativamente cercanos, los medios de comunicación eran muy difíciles. Bogotá, la capital de la Nueva Granada, estaba a 
su vez bastante lejana, a más de un mes de camino, por trocha y por el río Magdalena, lo cual dificultaba la rápida toma de decisiones. De allí la importancia, para ellos, los panameños, de que el Estado fuera federal y no centralista.

\section{IMPORTANCIA DE PANAMÁ}

Cuando el suizo Juan Augusto Suter descubrió la riqueza de California, perdida por México en la guerra con los Estados Unidos, comenzó una inmigración en la búsqueda del oro. Los aventureros necesariamente debían pasar por Panamá antes de seguir su destino hacia el norte. Esa región, que había sido centro obligado del comercio entre España y las colonias americanas, volvió a ocupar lugar preponderante a escala mundial.

Los buscadores de oro remontaban el río Chagres hasta Cruces y Gorgona y de allí, a lomo de mula, se trasladaban a Panamá en donde esperaban el barco que debía conducirlos a las pródigas minas. Éste tráfico enriquecía a ojos vista a las olvidadas y pobres provincias y preludiaba una era de adelanto para Panamá. Aún en los propios Estados Unidos, para ir de Nueva York a California, es decir de la costa este a la oeste, también debían coger el camino por Panamá.

La importancia que adquiría el istmo hizo imperativo buscar la comunicación de los océanos Atlántico y Pacífico. Entonces era una novedad el ferrocarril y comenzó a trabajarse en ese proyecto. Tras varios proyectos fallidos, finalmente el 19 de julio de 1848 el presidente José Hilario López firmó el contrato que otorgó a la sociedad estadounidense Compañía del Ferrocarril de Panamá el "privilegio" -así se llamaba a lo que hoy se conoce como concesión-, de construir el ferrocarril que conectaría a las ciudades de Panamá, en el Pacífico, y Portobelo, en el Atlántico.

La obra se inició en mayo de 1850 y se concluyó el 27 de enero de 1855. Así quedó unida --ipor fin!- la isla de Manzanillo, cerca de la desembocadura del río Chagres, con la ciudad de Panamá. Fue el octavo ferrocarril que se construyó en el mundo, después de los de Inglaterra, Francia, Austria, Estados Unidos, Rusia, Dinamarca y Suiza.

Fue un gran negocio el ferrocarril: andaba sobre rieles. Durante catorce años fue uno de los mejores negocios del mundo, hasta la entrada en servicio de los ferrocarriles transcontinentales de los Estados Unidos. El presidente colombiano Santos Gutiérrez, en un mensaje al Congreso de 1868, revelaba que en el año fiscal anterior el ferrocarril generaba más del diez por ciento de los ingresos fiscales de la nación, sin tener en cuenta las rentas de aduana que se causaban en Panamá. Mejor dicho, iban en coche.

Pero si bien la vía férrea era algo que necesitaba Panamá, no era lo definitivo. Quedaba pendiente lo fundamental, lo que iba a marcar su futuro: la excavación del canal interoceánico. Al mismo tiempo los gobiernos de la época tenían conciencia de la importancia que adquiría Panamá pero igual sabían que les era imposible protegerla militarmente. Por eso en 1841 el presidente Mariano Ospina Rodríguez firmó un acta de compromiso con el encargado de negocios de la Gran Bretaña, Pitt Adams, sobre protección de la soberanía colombiana en el istmo.

Naturalmente produjo controversia, sobre todo en los Estados Unidos en donde lo consideraban violatorio de Doctrina Monroe que se basada en la premisa de "América para los americanos". Por eso, el 
12 de diciembre de 1846 se firmó el tratado Mallarino-Bidlack, llamado así por haberlo suscrito Manuel María Mallarino, ministro de Relaciones Exteriores de Mosquera, y Benjamín A. Bidlack, encargado de negocios de los Estados Unidos.

Allí se decía: "El gobierno de la Nueva Granada garantiza al gobierno de los Estados Unidos que el derecho de vía o tránsito del istmo de Panamá, por cualesquiera medio de comunicación que ahora existan o en lo sucesivo puedan abrirse, estará franco y expedito para los ciudadanos y el gobierno de los Estados Unidos".

Comenzaban, pues a entregarle la soberanía a los colosos del norte. Posteriormente en 1850, los Estados Unidos y la Gran Bretaña suscribieron el tratado Clayton-Bulwer en donde las dos potencias se comprometían a tratarse con respeto en la búsqueda de un canal por Centroamérica.

\section{EL FEDERALISMO Y PANAMÁ}

Como se relató atrás, Panamá se reintegró a la república en 1841 con el firme propósito de lograr un estado federal pero guardaron discreción frente a las constituciones que se adoptaron inmediatamente después y lo hacían en atención a que gobierno debatía la construcción de su ferrocarril. Esos estatutos no sólo fueron centralistas sino además muy conservadores.

La Constitución de 1843 acabó con el sufragio universal, señalando que sólo podían votar quienes supieran leer y escribir o tuvieran un capital de más de trescientos pesos o renta anual de ciento cincuenta; suprimió el Consejo de Estado y en su lugar creó el Consejo de Gobierno, compuesto por el vicepresidente de la República y los secretarios de
Estado; otorgó al presidente de la República la facultad de nombrar y remover libremente a los gobernadores de las provincias; elevó a seis años el período mínimo de los magistrados de la Corte Suprema de Justicia y de los Tribunales Superiores; dispuso que los primeros fueran elegidos por el Congreso pleno y los últimos por el Gobierno, de ternas elaboradas por las Cortes. Como la de 1830, la Constitución de 1843 sirvió de antecedente a la Constitución de 1886.

Con la elección de José Hilario López el 7 de marzo de 1849, algunos de nuestros historiados constitucionales ven allí el nacimiento de los dos partidos históricos, el liberal y el conservador. Entre otros José María Samper, a pesar de que Tulio Enrique Tascón señala que ese día no se debatieron doctrinas sino candidatos. Pero la verdad fue que a partir de esa administración se iniciaron las grandes reformas radicales que fueron postulados de lo que sería el Partido Liberal (Tascón, 1951, pp.73)

La verdad fue que el año anterior, 16 de julio de 1848, apareció publicado en el periódico bogotano "El Aviso" un extenso artículo de Ezequiel Rojas bajo el título "La razón de mi voto" en donde proclama a José Hilario López como candidato del grupo liberal que se había reunido el 30 de junio de ese año para escoger ellos (fueron 28) al candidato que debía reemplazar al general Mosquera. Allí Rojas expuso además la que sería la primera plataforma doctrinaria del liberalismo colombiano.

El Congreso de 1851, de mayoría liberal, implantó una serie de reformas revolucionarias, de las cuales la más trascendental fue la del 21 de mayo, que decretó la libertad de los esclavos; consagró la absoluta libertad de imprenta; estableció el juicio por jurados 
para los delitos de homicidio, robo y hurto de mayor cuantía; prohibió el empleo de la fuerza pública para compeler el cumplimiento de los votos monásticos; extinguió todo fuero o privilegio eclesiástico e invocando el ejercicio del Real Patronato dictó leyes que provocaron conflictos entre la potestad civil y la potestad eclesiástica y que a la postre condujeron a la separación de la Iglesia y del Estado.

Luego, en 1853 se expidió la Constitución Centro Federal o de la Confederación Granadina en donde desaparecieron los departamentos, y las provincias quedaron con el poder municipal en toda su amplitud, con posibilidades de organizarse sin invadir las atribuciones del gobierno central. Gracias a esta independencia, cada provincia tramitó su propia constitución. ${ }^{1}$

Con este nuevo ordenamiento se abrió el camino federalista, al mismo tiempo que se complacía a los panameños dándoles un tratamiento especial a esa lejana región por la importancia que adquiría al ser tránsito hacia California, en donde se vivía la fiebre del oro. El Congreso de 1854 expidió así un acto legislativo adicional que creó el Estado de Panamá que algunos consideraron que no encajaba dentro de un Estado unitario.

El artículo $1^{\circ}$. de ese acto adicional llamaba a Panamá como "Estado federal soberano, parte integrante de la Nueva Granada”. Eso era un antagonismo de soberanías y se condenaba a la república a una capitis diminutio, creándose una situación anormal. El artículo 3․ redujo a sólo ocho los negocios en que podía intervenir la república frente al Estado de Panamá, tales como las relaciones exteriores y la organización y servicio del ejercito permanente y de la marina de guerra. En cambio, el istmo tenía soberanía y libertad en todos los ramos de la legislación civil, penal, comercial, judicial, procedimientos, policía, etc. y la peligrosa facultad de mantener milicias propias equivalentes al ejército nacional.

El panameño José de Obaldía, como vicepresidente y encargado del Poder (el titular era José Hilario López), tuvo la fortuna de sancionarla el 27 de febrero de 1855, un mes antes de entregar el gobierno al vallecaucano Manuel María Mallarino. Este acto adicional era un gesto para que Panamá continuara en la Nueva Granada, ante las insistentes amenazas de separarse. De esa manera se atendió una insistente propuesta del panameño Justo Arosemena.

El presidente del Senado de la época, Pedro Fernández Madrid, al firmar esa ley, pronunció estas palabras que resultaron premonitorias: "Voy a dar mi voto al proyecto de ley que crea el Estado de Panamá porque conozco la necesidad que tiene el istmo de constituirse sobre las bases del self-government, pero no se me oculta que éste no es sino el primer paso que da hacia la independencia aquella sección de la república. Tarde o temprano el istmo de Panamá será perdido para la Nueva Granada”.

Pero la desmembración de la república no se quedaba ahí. El artículo 12 del mismo acto, señalaba:

“Artículo 12.- Una ley podrá erigir en Estado, que sea regido conforme al presente acto legislativo, cualquier porción del territorio de la Nueva Granada. La ley que
Luego, en 1853 se expidió la Constitución Centro Federal o de la Confederación Granadina en donde desaparecieron los departamentos, y las provincias quedaron con el poder municipal en toda su amplitud,con posibilidades de organizarse sin invadir las atribuciones del gobierno central.

1. Sobre este tema, véase: Samper, José María. Derecho Público Interno de Colombia. Tomo II. Bogotá. Biblioteca Banco Popular, 1974, p. 226. Restrepo Piedrahíta, Carlos. Constituciones de la Primera República Liberal (cinco tomos). Bogotá. Universidad Externado de Colombia, 1979, 1985 
contenga la erección de un Estado, tendrá la misma fuerza que el presente acto de reforma constitucional, no pudiendo ser reformado sino por los mismos trámites de la Constitución".

Con este nuevo ordenamiento constitucional se abrió camino el espíritu federalista con una Constitución unitaria y disparó la creación de nuevos Estados soberanos. Con idénticos parámetros se crearon los Estados de Antioquia, Santander, Cauca, Cundinamarca, Boyacá, Bolívar y Magdalena.

Ante el contrasentido de tener una Constitución unitaria centralista con Estados federales, se hizo necesario hacer consecuente la normatividad nacional y establecer un sistema federal. Con ese propósito de expidió el acto legislativo del $10 \mathrm{de}$ febrero de 1858, que dispuso:

"Artículo 1․ La Constitución puede adicionarse o reformarse en todo o en parte de la misma manera que se adiciona o reforma una simple ley.

"Parágrafo.- Si las Cámaras legislativas lo tuvieren por conveniente, podrán reunirse en Congreso y allí en tres debates acordarán el acto o actos de adición o reforma de la Constitución.

"Artículo 2o. El acto o actos que se expidan por el Congreso con el fin de adicionar o reformar la Constitución, por los términos que establece el artículo anterior, no podrán ser objetados por el poder ejecutivo".

En desarrollo de la anterior facultad el Congreso expidió una nueva Constitución el 22 de mayo de 1858, señalando en su preámbulo que "en consecuencia de las variaciones hechas en la organización polí- tica de la Nueva Granada por los actos legislativos que han constituido en ella ocho Estados federales, son necesarias disposiciones constitucionales que determinen con precisión y claridad las atribuciones del Gobierno general y establezcan los vínculos de unión que deben ligar a los Estados".

Se había elegido presidente de la República al primero de los Ospina que han gobernado este país, Mariano Ospina Rodríguez. Él, que había sido conspirador en la noche septembrina contra el Libertador, fue después fundador del Partido Conservador y en ésta oportunidad, como jefe del Estado, se vanagloriaba de su condición de católico, apostólico y federalista. Pero al mismo tiempo, unido al Procurador de la época, Florentino González, defendió una verdadera y propia Constitución federal, la de la Confederación Granadina; pero, señalaba el jefe del Ministerio Público, que si no se adoptaba el proyecto, se decretase la anexión del territorio granadino a los Estados Unidos de América. Este pensamiento lo compartió el primer mandatario.

Finalmente esta propuesta alternativa se desechó y se aprobó una nueva Constitución, el 22 de mayo de 1858, respetando los ocho Estados federales que se habían creado. José de la Vega sostiene que "los constituyentes de 1858 claudicaron en la línea esencial del programa conservador, y desgraciadamente no sólo en esa sino en casi todas". 2

Al adoptarse esta Constitución, el general Tomás Cipriano de Mosquera, presidente del Congreso, declaró: "Hoy termina la revolución iniciada el 20 de julio de 1810;

2. De la Vega, José. La Federación en Colombia, Bogotá. Biblioteca de Autores Colombianos. Ministerio de Educación, 1952.p. 171 
han triunfado por fin nuestras virtudes cívicas. La federación está constituida”.

Pero una cosa era Ospina Rodríguez haciendo profesión de fe federalista y otra muy distinta como presidente. Le salió el godo. Actuaba con sectarismo manifiesto dando únicamente participación al Partido Conservador, en contraste con lo que había hecho su antecesor, Manual María Mallarino, quien hizo un gobierno con participación de los nacientes partidos. Ospina logró que el Congreso aprobara leyes encaminadas a robustecer el poder central en detrimento de los Estados.

Esas disposiciones fueron mal recibidas por los Estados y ello dio lugar a una nueva guerra, la conocida como de 1860 , y que ha sido la única revolución que ha triunfado en nuestro país. Los disturbios se presentaron en Santander, Cauca, Bolívar y Magdalena. En el Cauca lo inició su gobernador, el general Tomás Cipriano de Mosquera y para lograr su propósito buscó a su pariente, pero eterno enemigo, el general José María Obando. Con el fin de combatir a Ospina olvidaron sus viejas disputas.

\section{CUARTA SEPARACIÓN}

Panamá no era muy dada a la guerra, tanto que la independencia de España y las separaciones de Colombia, aún la última y definitiva, las hicieron sin un solo disparo. En las únicas guerras en que participaron fueron en la de 1885 y en la de los Mil Días. En la primera su intervención fue breve porque en la Ciudad de Panamá las fuerzas radicales, al mando del general Rafael Aizpuru, tuvieron que rendirse el 29 de abril de 1885 al general Carlos A. Gónima y al general Rafael Reyes, quien llegó procedente de Buenaventura.
Más prolongada fue la participación de Panamá en la guerra de los Mil Días pero se debió a que el general Benjamín Herrera la trasladó para allá. En ella participó activamente el panameño Belisario Porras que, por lo demás era hijo de cartagenero y quien luego de la de separación definitiva y creada la República de Panamá, fue sobresaliente dirigente político y presidente.

Cuando Mosquera inició la guerra contra el gobierno de Mariano Ospina Rodríguez, al Estado de Panamá lo presidía José de Obaldia, de familia de terratenientes y quien había sido presidente interino de la Nueva Granada luego de derrotar al general José María Melo en 1854, quien a su vez le había dado golpe de estado al general José María Obando. En el conflicto de 1860, Obaldia se declaró neutral y Panamá permaneció ajena a esa contienda y separada de la república. Fue tal su aislamiento con el gobierno de Ospina y el revolucionario de Mosquera que el gobernador llamó a elecciones para ese bienio en las que salió vencedor el conservador Santiago de la Guardia.

Caído el gobierno de Ospina, el 18 de julio de 1861 llegó victorioso de Bogotá el general Mosquera con el pomposo título de Presidente Provisorio de los Estados Unidos de la Nueva Granada y Supremo Director de la Guerra. Además se sentía el nuevo Libertador y como tal empezó a revivir el viejo sueño de Bolívar: la Gran Colombia. Y pensaba no sólo en lo que existió (Venezuela, Ecuador y Panamá), sino también con Costa Rica y otras naciones hispanoamericanas que seguirían uniéndose, conservando cada una de ellas su individualidad, sus leyes, su ejército, sus costumbres pero formando un solo y formidable Estado en cuya cúspide estaría
Panamáno era muy dada a laguerra, tanto que la independencia de España y las separaciones de Colombia, aún la última $y$ definitiva, las hicieron sin un solo disparo. 
él, coronado de gloria y dominando todo el panorama.

Buscó a Panamá y después de varias conversaciones entre su emisario Manuel Murillo Toro y el gobernador Santiago de la Guardia, suscribieron el llamado Convenio de Colón el 6 de septiembre de 1861, resultado de las reuniones que habían sostenido. Allí se dispuso:

"El Estado federal de Panamá se incorpora a la nueva entidad nacional que se denomina Estados Unidos de la Nueva Granada de Colombia y queda en consecuencia formando uno de los Estados soberanos federales que componen dicha asociación en los términos del Tratado que se ajustó en Cartagena el 10 de septiembre de $1860^{3 *}$ entre los plenipotenciarios de los Estados de Bolívar y Cauca, al cual adhiere el Estado de Panamá con las mismas reservas y condiciones".

Cuando se reunió la Convención de Rionegro para expedir la nueva Constitución, el delegado panameño, Buenaventura Correoso, aclaró en una constancia que dejó el 28 de febrero de 1863 , que ellos participaban en ese certamen como simples observadores y que él "se encontraba en una situación excepcional porque el Estado que representaba apenas estaba ligado por simpatía a los Estados que componían la Unión Colombiana”.

Iniciadas las sesiones, los diputados Camilo A. Echeverri, Aquileo Parra, Estanislao Silva, Felipe Zapata y Alejandro Gómez Santos, presentaron una iniciativa señalando a Panamá como capital. Decía así:

"Artículo 10. Designase para capital de los Estados Unidos de Colombia la ciudad de Panamá.
"Artículo 2. El Poder Ejecutivo dispondrá lo conveniente para la pronta traslación de las oficinas del Gobierno Federal a la ciudad capital, de manera que el próximo congreso se reúna en ella.

"Presentado a la Convención Nacional el 4 de marzo de 1863 ".

Para ponencia se le entregó el proyecto al general Tomás Cipriano de Mosquera quien en un largo escrito de 17 páginas -cuyo documento original tuve la fortuna de encontrar--, hizo una muy documentada defensa de la propuesta, señalando además que "Bolívar consideraba el istmo de Panamá como la joya más preciosa de Colombia y el asiento natural del gobierno de una nacionalidad respetable que trajera por resultado la consolidación de las instituciones republicanas en el Nuevo Mundo".

Allí criticaba la lejanía de Bogotá y señalaba que el punto más conveniente "es aquel en que las relaciones directas del Gobierno Nacional con las potencias extranjeras sean más fáciles y prontas".

Sin embargo elogia a Bogotá y anota que trasladada la capital a Panamá, aquella debe quedar como ciudad federal, con administración propia municipal, dependiente del Gobierno Nacional y ser el asiento del Ateneo Colombiano, "compuesto de la Escuela Politécnica, la Central de Artes y Oficios, la Academia de Medicina, el Instituto de ciencias políticas morales, naturales y físicas, a cuyo servicio y cuidado estarán el Museo y la Biblioteca nacional que contengan todo lo relativo a antigüedades del país y los archivos del virreinato de la antigua Colombia y Nueva Granada".

3. ${ }^{\star}$ Hace referencia a un tratado que firmaron Mosquera, por el Cauca y Juan José Nieto, por Bolívar, en donde se comprometían, tan pronto concluyera la guerra, a convocar una convención para crear los Estados Unidos de la Nueva Granada. Sería la Convención de Rionegro y a la nación finalmente se llamó Estados Unidos de Colombia. 
En la misma ciudad, afirma más adelante, "debe establecerse una fábrica de armas de toda clase y otra de pólvora, de manera que la defensa interior no dependa de una importación eventual de armas extranjeras".

Es posible que entre los incentivos que le dio Mosquera a los panameños para que se volvieran a anexar a Colombia estaba el de trasladar para el istmo la capital de la república. Esto no hay que descartarlo porque todo es posible en una personalidad como la del general caucano. Así mismo, cuando Panamá actuó de pleno derecho en la Convención, eligieron como presidente de la misma al panameño Justo Arosemena, adalid del federalismo, y en calidad de tal el 8 de mayo sancionó la Constitución de 1863.

La iniciativa de cambiar la capital de la nación fue negada, así como muchas otras propuestas de Mosquera. Ha sido costumbre en estos países que las constituciones se expiden con vista a un hombre. Entre nosotros la de 1830 se expidió para Bolívar y la de 1886 para Núñez. En cambio la de 1853 se expidió contra Obando y la de 1863 contra Mosquera, a pesar de que fue él quien la promovió.

\section{EL CANAL DE PANAMÁ}

La historia del canal de Panamá, que más parece una historieta o una comedia en un sin número de actos, se inició con el interés francés de llevarlo a cabo, sobre todo por su tecnología y profesionalismo, puesto a prueba por el vizconde Ferdinand de Lesseps, quien había trabajado en el servicio diplomático, había sido asesor de Mohammed Said de Egipto y, lo más importante, había construido el canal de Suez en 1869.
El Congreso Geográfico Internacional, reunido en París en 1875, nombró un comité para que estudiara la posibilidad de construir un canal por Panamá. Como resultado de ello la Societé Civile Internacionale $d u$ Canal Interoceanique de París envió a uno de sus fundadores, Lucien Napoleón Bonaparte Wyse, hijo ilegítimo de la sobrina de Napoleón I, la princesa Leticia, y del barón Jacques de Reinach, un banquero alemán residente en Francia. El propósito era conseguir la licencia para la construcción de esa obra. Y qué mejor para ese propósito que un personaje de su ancestro, así fuera ilegítimo. Llegó de Paris - porque no solo los bebés llegan de París-y su misión la cumplió en un tiempo record, pese a los trámites burocráticos que desde entonces ya existían en esta naciente república. Además fue objeto de numerosas atenciones de la gran sociedad de la época, a pesar de que la sangre azul del aristócrata visitante era bastante desteñida.

Gobernaba el país en 1878 el presidente Aquileo Parra y el secretario del Interior y Relaciones Exteriores era el general Eustorgio Salgar. El 13 de marzo, Bonaparte presentó sus poderes, el contrato de concesión se firmó siete días después (20 de marzo), con base en la ley 33 de 1876 que daba facultades al gobierno para esos efectos y luego se aprobó la ley 28 de 1878 que adoptó el convenio. Ella se sancionó el 18 de mayo por el nuevo gobierno de Julián Trujillo que se había iniciado el $1^{\circ}$. de abril. Como se ve, en apenas dos meses y una semana se hizo realidad el tan esperado deseo. ¿Esto fue ejemplo de rapidez oficial y eficacia legislativa, o la figura aristócrata facilitó los trámites, o se iniciaron allílos sobornos, las mordidas, a que estamos hoy acostumbrados, porque a quien parte
La historia del canal de Panamá, que más parece una historieta o una comedia en un sin número de actos, se inició con el interés francés de llevarlo a cabo, sobre todo por su tecnología y profesionalismo. 
y reparte le toca la Bonaparte? ¿Será válida alguna de esas preguntas o todas las anteriores?

El acuerdo con Colombia le daba a la Societé Civile el derecho exclusivo de construir un canal a nivel del mar bajo una concesión de 99 años. Quedaba terminantemente prohibido a la Compañía venderle la concesión a otro gobierno. Los franceses lograron ese acuerdo con la promesa de que para 1882 se habrían depositado 7’500.000 francos en un Banco de Londres, como pago a Colombia.

A su regreso a París, Bonaparte se aprovechó de la alegría que por la obra expresaba Lesseps, quien entonces ya era un anciano de 70 años, retirado de compromisos pero que gozaba de la gloria de haber construido el canal de Suez. El famoso personaje aceptó y se entusiasmó tanto que la obra del canal de Panamá la comenzó a principios de 1880.

Al poco tiempo de iniciados los trabajos los franceses comenzaron a ser víctimas de las tierras y las selvas panameñas. Era un lugar en donde la mano del hombre no había puesto el pie. Encontraron un enemigo implacable que Lesseps no había previsto ni soñado: mosquitos y zancudos que atacaban sin piedad ni misericordia y que no solamente acabaron con muchas vidas sino que principiaron a hacerles perder la moral. En pocos meses murieron 16.000 hombres en las selvas inhóspitas, en las lagunas deletéreas y en los pantanos del istmo.

El historiador inglés James A. Fraude, después de su visita a Panamá, dio sobre esa empresa el siguiente concepto, bien severo por cierto:

"No hay quizás en el mundo un lugar en que se hayan dado cita tantas estafas y villa- nías, tantas enfermedades y pestilencias, tanto estercolero de abominación moral y física, como en la escena de esta famosa empresa de ingeniería del siglo XIX”.

Año tras año se contrataban nuevos empréstitos, sin que la obra avanzara. Empezaron a circular rumores sobre malos manejos y sobre turbias especulaciones que iban en detrimento del crédito de la compañía. Se modificaron los planos primitivos para cambiar el proyecto del canal a nivel por las esclusas y, mientras tanto, vino la desorganización de los trabajos. El fracaso del último empréstito determinó la bancarrota de la empresa, ya que todos los esfuerzos para allegar nuevos recursos fueron inútiles. Después de la quiebra surgieron nuevos proyectos para revivir la empresa pero el desprestigio en que había caído hizo infructuosa toda iniciativa pues las acciones de 500 francos descendieron en el mercado bursátil a 27, es decir, casi a la vigésima parte.

En 1885 sólo se había completado una décima parte del canal. Las empresas de Lesseps estaban pagando cerca de 15 millones de dólares en intereses sobre los empréstitos. Pasaron a la administración judicial y en 1894 los tribunales franceses reorganizaron la entidad bajo el nombre de la Nueva Compañía Francesa del Canal.

De otra parte, el gobierno de Colombia, necesitando fondos para atender los gastos de la guerra de los Mil Días, le concedió a la compañía francesa, ante tan difícil situación, un plazo adicional de seis años.

Mientras tanto, en febrero de 1889, el Congreso de los Estados Unidos estableció la Comisión Marítima de Nicaragua, una entidad privada para la construcción de un 
canal en ese país. Después de tres años se habían agotado los fondos y la crisis financiera de entonces puso fin al trabajo de construcción iniciado en la costa oriental de ese país centroamericano, en el puerto de Greytown (San Juan del Norte).

Los Estados Unidos de Norteamérica, que creen que también son los Estados Unidos de Centro y Suramérica, seguían empeñados en esa ruta y por eso crearon una nueva comisión para determinar la bondad de ese proyecto. Cuando se completó el estudio, a finales de 1899, se le ordenó a la comisión que investigara los posibles sitios, no sólo por Nicaragua -que había sido la primera alternativa--, sino también por Panamá.

En el proyecto del Canal de Panamá quedaron sepultados los sueños del anciano y entusiasta Ferdinand de Lesseps, cuyos ingenieros y trabajadores sucumbieron ante la naturaleza bravía que les arrebató el alborozo de entregar a ese francés glorioso un segundo canal de Suez. Y en ese entonces el moderno y pujante imperio del norte, la superpotencia naciente que había desalojado a España del Caribe y de las islas Filipinas, hizo sonar sus pasos en la proximidad del istmo con la resolución irrevocable de conectar los dos mares a lo largo de una franja estratégica que sería de su propiedad por casi cien años, con todas las consecuencias inherentes a dicho monopolio.

El problema que tenían los Estados Unidos, si continuaban ellos las obras del Canal de Panamá desistiendo del canal por Nicaragua, era el tratado Clayton-Bulwer, suscrito con la Gran Bretaña, que obligaba a ambas naciones a guardar neutralidad y les impedía a ellos realizar en el istmo cualquier obra en detrimento del otro.
Pero los Estados Unidos lograron abrogar dicho pacto, reemplazándolo con el tratado Hay-Pauncefote en donde se dispuso que ellos podían terminar el canal de Panamá, tener y disfrutar de todos los derechos y la exclusividad de proveer a la reglamentación y organización de la obra.

Ante estos hechos, ocurridos a comienzos de 1901, Colombia inició la discusión de un tratado con los Estados Unidos, complicado desde el inicio. Envió primero a Carlos Martínez Silva y, ante el fracaso de éste, a José Vicente Concha, quien tuvo idénticos resultados. Al final, el 22 de enero de 1903, le correspondió al encargado de negocios Tomás Herrán, la difícil misión de discutirlo y firmarlo. Él que era un profesional en el tema, advirtió reiteradamente que si no se suscribía se iba perder Panamá, como en efecto sucedió.

No fue ningún pintado en la pared. Había nacido en el Palacio Presidencial por ser hijo de Pedro Alcántara Herrán y nieto de Tomás Cipriano de Mosquera, ambos presidentes. Tenía una maestría en Artes en la Universidad Georgetown, al mismo tiempo que estudió griego, latín, redacción inglesa, lenguas modernas, matemáticas, química y física. Llegó a tener pleno dominio del alemán, francés e inglés.

El tratado se conoció como HerránHay y en Colombia don Miguel Antonio Caro encabezó la oposición porque no le perdonó jamás a Marroquín su deslealtad para con él-que fue quien lo propuso para vicepresidente - y la toma del poder el 31 de julio de 1900, cuando desalojó de la Presidencia al titular, el anciano Manuel Antonio Sanclemente. El tratado lo negó el Senado por unanimidad el 2 de septiembre de 1903. 
La verdad era que Panamáse sentía olvidada delcentro depoder en Bogotá. No solo por la lejanía sino porque consideraban en el istmo que le ponían palos en la rueda paraquese concluyeran las obras del canal, impidiendo una solución económica a la crisis, bien con los franceses, con los ingleses o con los americanos del norte.

\section{RAZONES DE LA ÚLTIMA SEPARACIÓN}

La verdad era que Panamá se sentía olvidada del centro de poder en Bogotá. No solo por la lejanía sino porque consideraban en el istmo que le ponían palos en la rueda para que se concluyeran las obras del canal, impidiendo una solución económica a la crisis, bien con los franceses, con los ingleses o con los americanos del norte. Se anexaron nuevamente a los Estados Unidos de Colombia en la Convención de Rionegro con ese propósito y no encontraron resultados.

Por su distancia de los poderes públicos, por su condición geográfica privilegiada, esperaban un tratamiento especial, sobre todo en un Estado federal, como lo consiguieron en las Constituciones de 1853, 1858 y en la de 1863 . Tras el triunfo de la Regeneración de Rafael Núñez, paradójicamente muy vinculado a Panamá -nada menos que de allá fue su primer amor--, a ellos no se les tuvo en cuenta. Los delegatarios de esa región a las deliberaciones de la Constitución de 1886, fueron escogidos a dedo por el Gobierno y resultaron sus voceros Miguel Antonio Caro, quien no conocía ni el mar, ni el río Magdalena y aún menos a Panamá, y además encabezaría en 1903 la oposición en el Senado al tratado HerránHay, y el otro fue Felipe Fermín Paúl, bogotano, de ascendencia venezolana, hermano de monseñor José Telésforo Paúl, arzobispo de Bogotá durante la Regeneración y gran amigo de Núñez.

No se sintieron representados en las deliberaciones de esa Constitución que, por lo demás, fue centralista y unitaria, lo que consideraban atentaba contra la autonomía e independencia de una región que por su condición geográfica necesitaba un régimen federal.
Sin embargo, al instalar el Consejo de Delegatarios, el presidente Rafael Núñez, dijo:

"(hay) la necesidad de mantener, durante algún tiempo, un fuerte ejército, que sirva de apoyo material a la aclimatación de la paz, que no puede ser producida instantáneamente por un sistema de gobierno que habrá de guardar escasa armonía con los defectuosos hábitos adquiridos en tantos años de error. El solo Estado de Panamá exige numerosa y bien pagada guarnición, a fin de que no sobrevengan de nuevo ocurrencias que puedan poner en peligro nuestra soberanía; sin que dicha precaución excluya la más segura, que es el atinado cultivo de nuestras relaciones con el Gobierno norteamericano, que acaba de darnos testimonio de su buena fe".

En el proyecto de Constitución sometido a consideración de la Asamblea de Delegatarios, en su artículo 74, luego de darle facultades al Congreso para modificar la división general del territorio, le daba además atribuciones para "disponer lo conveniente para la administración de Cundinamarca y Panamá”.

El tratamiento especial que merecía Panamá, con relación a otros departamentos por su condición geográfica especialísima, dio lugar a varios debates en el seno de esa asamblea, lo cual determinó que se aprobara finalmente el artículo 201 de la Constitución, que decía: "El departamento de Panamá está sometido a la autoridad directa del Gobierno, y será administrado con arreglo a las leyes especiales". Disposición que jamás se desarrolló.

\section{NUEVA PROPUESTA DE CAPITAL}

En este trabajo se han señalado las dos oca- 
siones en que se ha propuesto a Panamá como capital. Una fue el mismo Libertador, en la Carta de Jamaica y en la convocatoria al Congreso Afictiónico, y otra la del general Tomás Cipriano de Mosquera en la Convención de Rionegro cuyo original, repito, tuve la fortuna de encontrar y cuya fotocopia conservo. Pero hubo después otra propuesta similar y fueron los propios panameños quienes la rechazaron.

Mientras en noviembre de 1903 en Panamá se producían los hechos que llevaron a la separación, en la lejana Bogotá el vicepresidente Marroquín se la pasaba en Palacio en los habituales pasatiempos de los centenaristas (a pesar de que faltaban siete años para 1910): tomando chocolate y haciendo anagramas. Además de la distancia en kilómetros, las comunicaciones eran difíciles y coincidencialmente la víspera del día la separación --3 de noviembre-se dañó el cable submarino que unía a Buenaventura con el istmo, razón por la cual el gobierno colombiano no vino a enterarse de lo ocurrido sino tres días después a través de un cable fechado el día 4, desde Quito, enviado por el ministro colombiano en Ecuador, Emilio Isaza, y que pudo llegar luego de innumerables dificultades.

Hubo el llanto y crujir de dientes y lo único que se les ocurrió fue, no convocar un Consejo de Seguridad, como ahora lo hacen los presidentes después de cualquier tragedia, sino integrar una comisión que viajara a Panamá y los convenciera de retornar a la patria. Ésta quedó integrada por Rafael Reyes, quien la presidía como comandante en jefe de los ejércitos del Atlántico, el Pacífico y Panamá; y los otros generales Lucas Caballero, Jorge Holguín, Pedro Nel Ospina y Daniel Ortíz.
Partió por barco la comisión el 12 de noviembre con destino a Washington, previo intento de desembarcar en el istmo. Pero al llegar a Colón y descender de la embarcación, las autoridades militares de los Estados Unidos, que estaban allí, les impidieron entrar a la ciudad, viéndose obligados a regresar a la nave y seguir al país del norte con la vana ilusión de que los recibiera el presidente Roosevelt, lo cual nunca ocurrió.

El 11 de diciembre, es decir 38 días después de la separación, desde el Arlington Hotel de Washington, el general Reyes le escribió una carta a un amigo suyo panameño, José María Hurtado, quien se hallaba en Roma. Esta misiva, también, como el documento del general Mosquera en Rionegro, tuve la fortuna de encontrarlo y mantengo una copia del mismo.

El destinatario de la carta era un "estimado amigo" del general Reyes -así lo decía en el encabezado--, de gran prestigio, porque a pocos días de haberse constituido el nuevo gobierno del istmo ya le habían ofrecido una representación diplomática en Europa "seguramente bien pagada", según parecer del autor de la misiva. Sin embargo el señor Hurtado la declinó, razón por la cual el gobierno colombiano le había hecho saber que deseaba que fuera su embajador en la Santa Sede. A pesar de ello, comenta con escepticismo Reyes, que en la desorganizada Colombia de pronto "ya hubieran nombrado otro ministro, quizá Gutiérrez Ponce”. Se refiere a un personaje que siempre estuvo en el servicio diplomático.

En su carta, el general Reyes hace un relato de la situación del momento y sostiene que los Estados Unidos no retrocede- 
rán una línea del punto a donde han llegado

“y en esto están apoyados por la opinión pública, que es decididamente imperialista, por una gran mayoría de ambas cámaras y por el genio de conquistador del presidente Roosevelt, quien estigmatiza a todos los que lo acompañan en la administración”.

Señala que, en consecuencia, su misión diplomática se limitará a presentar al Departamento de Estado el Memorial de Agravios sufrido por Colombia, y que en ese momento prepara, por la violación del Tratado de 1840 y por haberse impedido el desembarque de las tropas para dominar la revolución de Panamá, reclamaciones que serían sometidas al Tribunal de La Haya o a un tribunal mixto, como el que falló la reclamación de Venezuela con las potencias europeas. Confía que de ese arbitramento salga la reintegración del Istmo a Colombia y que la capital de la república sea Panamá.
Le dice concretamente a su amigo que a los Estados Unidos le conviene "someter las reclamaciones de Colombia al arbitramento obrando de manera que lo que éste decida obligue también al nuevo gobierno de Panamá y dando a insinuar la idea que de ese arbitramento puede salir la reintegración de Panamá en Colombia, señalando para capital la $1^{\text {a }}$. ciudad". Es decir, nuevamente se plantea que Panamá sea capital.

Estoy convencido de que si el Senado de Colombia hubiera aprobado el tratado Herrán-Hay, no me cabe duda que Panamá no fuera capital de Colombia pero otra habría sido nuestra suerte, sin Noriegas extraditados, sin reuniones de narcos en Panamá, y también nuestra historia constitucional habría sido otra. Quizá tendríamos un sistema federal. Y como sucedió con Panamá, el canal ya fuera totalmente nuestro.

\section{Bibliografía}

1. CHONG M., Moisés. Historia de Panamá. (1973). San José de Costa Rica: Litografía e Imprenta LIL, p. 121.

2. TASCÓN, Tulio Enrique. Historia del Derecho Constitucional Colombiano. (1952). Bogotá: Ediciones Cátedra, 1951.pp. 73 ss. 